\title{
Sea Urchin-like Microstructures Pressure Sensors with Ultra-sensitivity and Super Working Range
}

\section{Xiu Wang}

Chongqing University

Lu-Qi Tao

Chongqing University

Min Yuan

Chongqing University

Ze-Ping Wang

Chongqing University

Jiabing Yu

Chongqing Unversity https://orcid.org/0000-0001-7206-6592

\section{Ding Xie}

Chongqing University

\section{Feng Luo}

Chongqing University

Xian-Ping Chen ( $\nabla$ xianpingchen@cqu.edu.cn )

Chongqing University

Ching-Ping Wong

Georgia Institute of Technology

\section{Research Article}

Keywords: pressure sensors, Sensitivity, sea urchin-like

Posted Date: September 18th, 2020

DOI: https://doi.org/10.21203/rs.3.rs-75243/v1

License: (c) (i) This work is licensed under a Creative Commons Attribution 4.0 International License. Read Full License

Version of Record: A version of this preprint was published at Nature Communications on March 19th, 2021. See the published version at https://doi.org/10.1038/s41467-021-21958-y. 


\section{Sea urchin-like microstructures pressure sensors with ultra- sensitivity and super working range}

Xiuman Wang ${ }^{1}$, Lu-qi Tao ${ }^{2}$, Min Yuan ${ }^{1}$, Zeping Wang ${ }^{1}$, Jiabing Yu ${ }^{1}$, Dingli Xie ${ }^{1}$, Feng Luo $^{1}$, Xianping Chen ${ }^{* 1,2} \&$ ChingPing Wong*3

${ }^{1}$ Key Laboratory of Optoelectronic Technology \& Systems, Education Ministry of China, Chongqing University and College of Optoelectronic Engineering, Chongqing University, Chongqing 400044, China

${ }^{2}$ State Key Laboratory of Power Transmission Equipment \& System Security and New Technology and School of Electrical Engineering, Chongqing University, Chongqing 400044, China.

${ }^{3}$ School of Materials Science and Engineering, Georgia Institute of Technology

*Corresponding author: xianpingchen@cqu.edu.cn cp.wong@mse.gatech.edu

\section{Abstract}

Sensitivity and pressure range are two significant parameters of pressure sensors.

The existing pressure sensors are difficult to achieve both high sensitivity and a wide pressure range. In this regard, we proposed a new pressure sensor with a ternary nanocomposite $\mathrm{Fe}_{2} \mathrm{O}_{3} / \mathrm{C} @ \mathrm{SnO}_{2}$. Notably, the sea urchin-like $\mathrm{Fe}_{2} \mathrm{O}_{3}$ structure promoted signal transduction and protected $\mathrm{Fe}_{2} \mathrm{O}_{3}$ needles from mechanical breaking; while, acetylene carbon black improved the conductivity of $\mathrm{Fe}_{2} \mathrm{O}_{3}$. Moreover, one part of $\mathrm{SnO}_{2}$ nanoparticles adhered to the surface of $\mathrm{Fe}_{2} \mathrm{O}_{3}$ needles and formed $\mathrm{Fe}_{2} \mathrm{O}_{3} / \mathrm{SnO}_{2}$ heterostructures whereas its other part of nanoparticles dispersed into the carbon layer and formed $\mathrm{SnO}_{2} @ \mathrm{C}$ structures. Collectively, the synergy of the three structures $\left(\mathrm{Fe}_{2} \mathrm{O}_{3} / \mathrm{C}, \mathrm{Fe}_{2} \mathrm{O}_{3} / \mathrm{SnO}_{2}\right.$ and $\left.\mathrm{SnO}_{2} @ \mathrm{C}\right)$ improved the limited pressure response range of a single structure. The experimental results demonstrated that the $\mathrm{Fe}_{2} \mathrm{O}_{3} / \mathrm{C} @ \mathrm{SnO}_{2}$ pressure sensor exhibits high sensitivity $\left(680 \mathrm{kPa}^{-1}\right)$, fast response $(10 \mathrm{~ms})$, broad range (up to $150 \mathrm{kPa}$ ), and good reproducibility (over 3500 cycles under a pressure of 110 $\mathrm{kPa}$ ). This implies that the new pressure sensor has wide application prospects especially in wearable electronic devices and health monitoring. 


\section{Introduction}

In the past few years, pressure sensors are considered promising candidates for use in wearable devices, electronic skins, and human-machine interfaces due to their low cost, flexibility, simple fabrication process, high integration potential, among others ${ }^{1-}$

${ }^{4}$. In particular, pressure sensors are classified into four main types namely: capacitive ${ }^{5-7}$, piezoresistive ${ }^{8-10}$, piezoelectric ${ }^{11-13}$, and triboelectric sensors ${ }^{14-16}$. Furthermore, piezoresistive pressure sensors have multiple benefits, including low energy consumption, easy signal collection, simple device assembly, and high sensitivity. Recently, different microstructure or nanostructure geometries such as (interlocked microstructures ${ }^{17}$, hollow-sphere microstructure ${ }^{18}$, micro-pyramid array ${ }^{19}$, and porous structure ${ }^{20}$ ) has been explored to improve the sensitivity of piezoresistive pressure sensors. Among them, the tapering geometry or spine structure confers a clever design that not only promotes signal transduction for high sensitivity, but also protects the bristle from mechanical breaking ${ }^{21,22}$. Similar structural has been employed in mechanical sensors and yielded enhanced sensing performance. For example, Yin et al. noted that $\mathrm{ZnO}$ sea urchin-shaped microparticles with a low-temperature solution process exhibited a high sensitivity of $121 \mathrm{kPa}^{-1}$ (pressure range $\left.0-10 \mathrm{~Pa}\right)^{23}$. Lee et al. achieved a sensitivity of $2.46 \mathrm{kPa}^{-1}$ (pressure range $0-1 \mathrm{kPa}$ ) with a piezoresistive pressure sensor based on sea-urchin shaped metal nanoparticles ${ }^{24}$. In another work by Shi et al. studied the urchin-like hollow carbon spheres, and the sensitivity reached $260.3 \mathrm{kPa}^{-1}$ at $1 \mathrm{~Pa}^{25}$. Based on the above background, the piezoresistive pressure sensors have high sensitivity only under a small pressure range. Additionally, without 
any additives, that is, relying only on its own structure and performance, it is difficult for the sensing material to achieve high sensitivity and wide pressure working range at the same time. Of note, the low conductivity of a single metal oxide semiconductor limits the pressure response range of the piezoresistive pressure sensors.

There are two widely researched metal oxide including $\mathrm{Fe}_{2} \mathrm{O}_{3}$ and $\mathrm{SnO}_{2}$, because of their low-cost, environmental friendliness, and natural abundance. Studies have reported that coupling metal oxide and carbon compounds to form metal oxide/C nanocomposite, may improve photocatalytic ${ }^{26}$ and electrochemical performances ${ }^{27}$. Despite metal oxide/C nanocomposite processing large specific surface area and strong conductivity, they have rarely been employed in fabricating flexible pressure sensors.

In this work, we proposed a nanostructure design of materials with ultra-sensitivity for an ultra-broad-range pressure sensor. Particularly, this strategy involves the use of acetylene black carbon as a carrier due to its strong conductivity and high specific surface. The acetylene black carbon encloses particles $\mathrm{Fe}_{2} \mathrm{O}_{3}$, thereby forming $\mathrm{Fe}_{2} \mathrm{O}_{3} / \mathrm{C}$ structure. Furthermore, one part of $\mathrm{SnO}_{2}$ nanoparticles were dispersed into the carbon layer and formed $\mathrm{SnO}_{2} @ \mathrm{C}$ structures, whereas its other part of nanoparticle adhered to the surface of $\mathrm{Fe}_{2} \mathrm{O}_{3}$ needles and formed $\mathrm{Fe}_{2} \mathrm{O}_{3} / \mathrm{SnO}_{2}$ heterostructures. Carbon improves the conductivity of a single metal oxide. Collectively, the synergy of the three structures $\left(\mathrm{Fe}_{2} \mathrm{O}_{3} / \mathrm{C}, \mathrm{Fe}_{2} \mathrm{O}_{3} / \mathrm{SnO}_{2}\right.$ and $\left.\mathrm{SnO}_{2} @ \mathrm{C}\right)$ improved the limited pressure response range of a single structure. Notably, the $\mathrm{Fe}_{2} \mathrm{O}_{3} / \mathrm{C} @ \mathrm{SnO}_{2}$ (3:1:4) pressure sensor exhibited high sensitivity $\left(680 \mathrm{kPa}^{-1}\right)$, fast response $(10 \mathrm{~ms})$, broad range (up to 150 $\mathrm{kPa}$ ) and good reproducibility (over 3500 cycles under a pressure of $110 \mathrm{kPa}$ ). 


\section{Results and discussion}

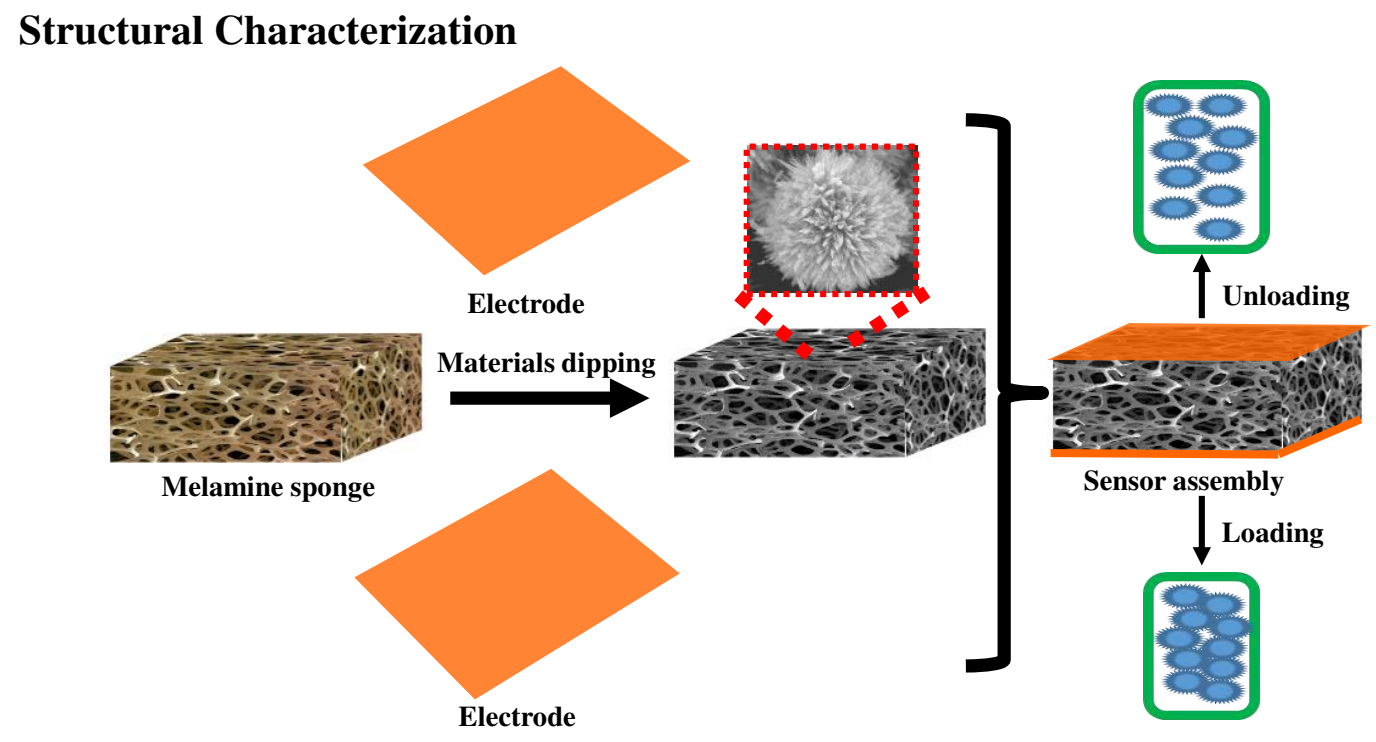

Fig. 1 Schematic illustration of the fabrication pressure sensor 



e
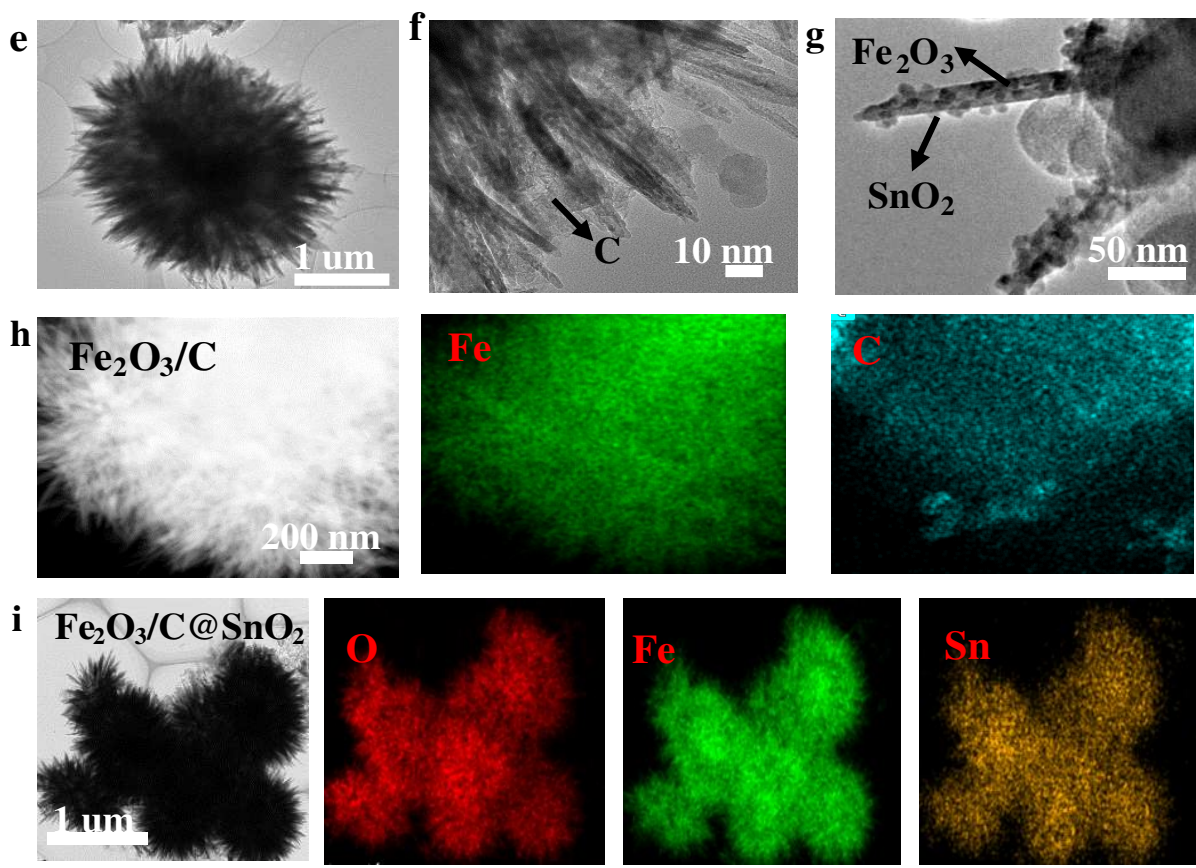

Fig. 2. a The XRD patterns of acetylene carbon black, $\mathrm{Fe}_{2} \mathrm{O}_{3}, \mathrm{SnO}_{2}, \mathrm{Fe}_{2} \mathrm{O}_{3} / \mathrm{C}$ (3:1) and $\mathrm{Fe}_{2} \mathrm{O}_{3} / \mathrm{C} @ \mathrm{SnO}_{2}$ (3:1:4). SEM images of $\mathbf{b} \mathrm{Fe}_{2} \mathrm{O}_{3}, \mathbf{c} \mathrm{Fe}_{2} \mathrm{O}_{3} / \mathrm{C}$ (3:1), and $\mathbf{d ~} \mathrm{Fe}_{2} \mathrm{O}_{3} / \mathrm{C} @ \mathrm{SnO}_{2}$ (3:1:4), TEM images of $\mathbf{e} \mathrm{Fe}_{2} \mathrm{O}_{3}$, $\mathbf{f} \mathrm{Fe}_{2} \mathrm{O}_{3} / \mathrm{C}$ (3:1), and $\mathbf{g} \mathrm{Fe}_{2} \mathrm{O}_{3} / \mathrm{C} @ \mathrm{SnO}_{2}$ (3:1:4), elemental mapping of $\mathbf{h}$ $\mathrm{Fe}_{2} \mathrm{O}_{3} / \mathrm{C}(3: 1)$, and $\mathbf{i} \mathrm{Fe}_{2} \mathrm{O}_{3} / \mathrm{C} @ \mathrm{SnO}_{2}(3: 1: 4)$. 
The fabrication process used in this study is illustrated in Fig. 1. First, conductive materials were synthesized using hydrothermal method. Then, a clean melamine sponge was soaked in the sample solution. Finally, after the electrode connection, a pressure sensor with a melamine sponge substrate was obtained.

The phase structure of acetylene carbon black, $\mathrm{Fe}_{2} \mathrm{O}_{3}, \mathrm{SnO}_{2}, \mathrm{Fe}_{2} \mathrm{O}_{3} / \mathrm{C}$ (the mass ratio of $\mathrm{Fe}_{2} \mathrm{O}_{3} / \mathrm{C} 3: 1$ ), and $\mathrm{Fe}_{2} \mathrm{O}_{3} / \mathrm{C} @ \mathrm{SnO}_{2}$ (the mass ratio of $\mathrm{Fe}_{2} \mathrm{O}_{3} / \mathrm{C} @ \mathrm{SnO}_{2}$ 3:1:4) was characterizated using X-ray diffraction (XRD), as depicted in Fig. 2a. The acetylene carbon black indicated a broad peak at $20^{\circ} \sim 30^{\circ}$, corresponding to its (002) crystal plane. The XRD pattern with (012), (104), (110), (113), (024), (116), and (125) was regarded as the formation of $\mathrm{Fe}_{2} \mathrm{O}_{3}$ (JCPDS 33-0664). The pristine $\mathrm{SnO}_{2}$ nanoparticles exhibited a tetragonal structure (JCPDS 41-1445). Remarkably, the diffraction peaks of acetylene carbon black and $\mathrm{Fe}_{2} \mathrm{O}_{3}$ was observed in $\mathrm{Fe}_{2} \mathrm{O}_{3} / \mathrm{C}$. Besides, as the carbon mass increased, the carbon peaks became stronger (Fig. S1a, Supporting information). The XRD pattern of the $\mathrm{Fe}_{2} \mathrm{O}_{3} / \mathrm{C} @ \mathrm{SnO}_{2}$ revealed sharp peaks, whereas all the diffraction peaks corresponded well with single acetylene carbon black, $\mathrm{Fe}_{2} \mathrm{O}_{3}$ and $\mathrm{SnO}_{2}$, and thus, indicating the $\mathrm{Fe}_{2} \mathrm{O}_{3} / \mathrm{C} @ \mathrm{SnO}_{2}$ nanocomposite with high purity. Notably, the peak of $\mathrm{SnO}_{2}$ was stronger in $\mathrm{Fe}_{2} \mathrm{O}_{3} / \mathrm{C} @ \mathrm{SnO}_{2}(3: 1: 8)$ nanocomposites, thus suggesting a higher content of $\mathrm{SnO}_{2}$ in this composite (Fig. S1b).

The microstructures of the $\mathrm{Fe}_{2} \mathrm{O}_{3}, \mathrm{Fe}_{2} \mathrm{O}_{3} / \mathrm{C}(3: 1)$, and $\mathrm{Fe}_{2} \mathrm{O}_{3} / \mathrm{C} @ \mathrm{SnO}_{2}(3: 1: 4)$ were characterized using scanning electron microscopy (SEM), transmission electron microscopy (TEM), elemental mapping, and high-angle annular dark-field scanning transmission electron microscopy (HAADF-STEM), which are shown in Fig. 2b-i. The 
images of $\mathrm{Fe}_{2} \mathrm{O}_{3}$ reflected a typical sea urchin-like structure, with a diameter of about $3 \mathrm{um}$, as indicated in Fig. 2b. The microstructure of $\mathrm{Fe}_{2} \mathrm{O}_{3} / \mathrm{C}$ nanocomposite is shown in Fig. 2c and Fig. 2f. In addition, a carbon material was embedded in the gap between adjacent $\mathrm{Fe}_{2} \mathrm{O}_{3}$ needles, thus forming $\mathrm{Fe}_{2} \mathrm{O}_{3} / \mathrm{C}$ structure. The SEM images of resulting $\mathrm{Fe}_{2} \mathrm{O}_{3} / \mathrm{C} @ \mathrm{SnO}_{2}$ (3:1:4), in which $\mathrm{SnO}_{2}$ nanoparticles are visible is elucidated in Fig. $2 \mathrm{~g}$. Besides, one part of $\mathrm{SnO}_{2}$ nanoparticles were well tightly attached to $\mathrm{Fe}_{2} \mathrm{O}_{3}$ needles, which indicates the formation of a heterojunction between the $\mathrm{Fe}_{2} \mathrm{O}_{3}$ and $\mathrm{SnO}_{2}$. Fig. S2i illustrates the interfacial structure of the $\mathrm{Fe}_{2} \mathrm{O}_{3} / \mathrm{C} @ \mathrm{SnO}_{2}(3: 1: 4)$, that was examined using a high-resolution TEM (HRTEM) technique. The $\mathrm{SnO}_{2}$ nanoparticles grew on the (104) surface of the $\mathrm{Fe}_{2} \mathrm{O}_{3}$, along the direction of (110) $\mathrm{SnO}_{2}$, and thereby forming (104) Fe2O3/ (110) $\mathrm{SnO}_{2}$ heterojunction. On the other hand, the other part of $\mathrm{SnO}_{2}$ nanoparticles penetrated the carbon layer, forming $\mathrm{SnO}_{2} @ / \mathrm{C}$ (Fig. 2g). It was noted that $\mathrm{Fe}_{2} \mathrm{O}_{3} / \mathrm{C} @ \mathrm{SnO}_{2}$ contains three structures composing of $\mathrm{Fe}_{2} \mathrm{O}_{3} / \mathrm{C}, \mathrm{SnO}_{2} @ / \mathrm{C}$, and $\mathrm{Fe}_{2} \mathrm{O}_{3} / \mathrm{SnO}_{2}$ heterojunction. Besides, as the mass of carbon and $\mathrm{SnO}_{2}$ increases, the carbon layer and $\mathrm{SnO}_{2}$ nanoparticles are more elucidated in the SEM images, as viewed in Fig. S2a-f, which was consistent with the XRD experimental results. The microstructure and compositional distribution of nanocrystals were further investigated using STEM and EDX mapping. The tin signal for $\mathrm{SnO}_{2}$, the iron signals for $\mathrm{Fe}_{2} \mathrm{O}_{3}$, and carbon signals overlapped completely across the entire sample, which implied that $\mathrm{Fe}_{2} \mathrm{O}_{3}$, carbon, and $\mathrm{SnO}_{2}$ were uniformly combined (Fig. 2h and Fig. 2i). 
a

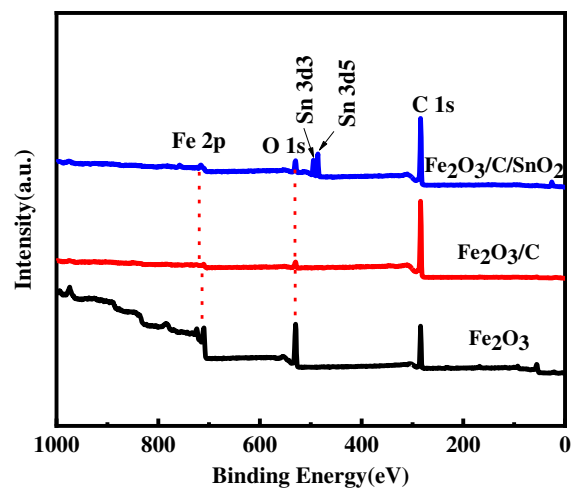

c

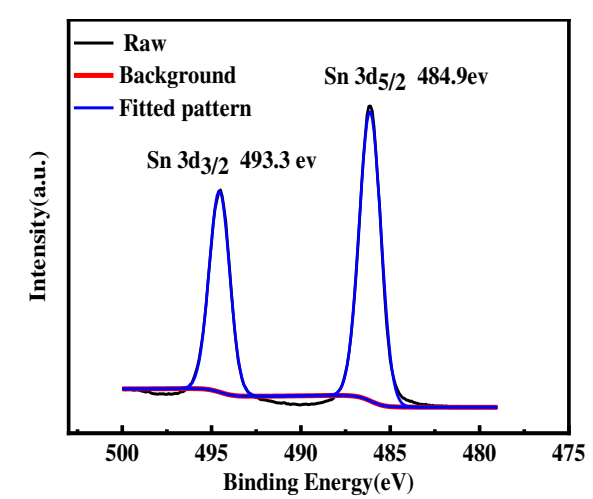

b

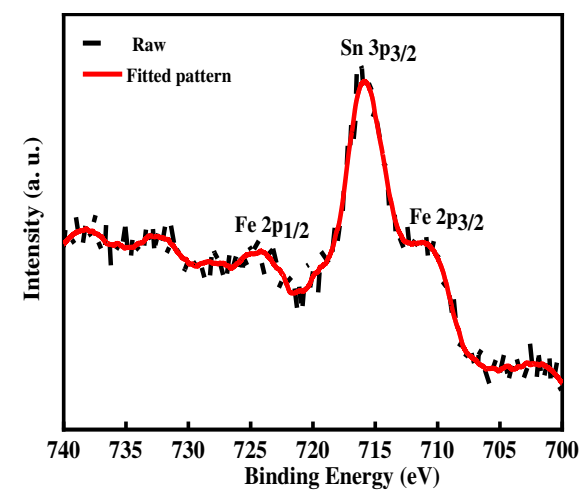

d

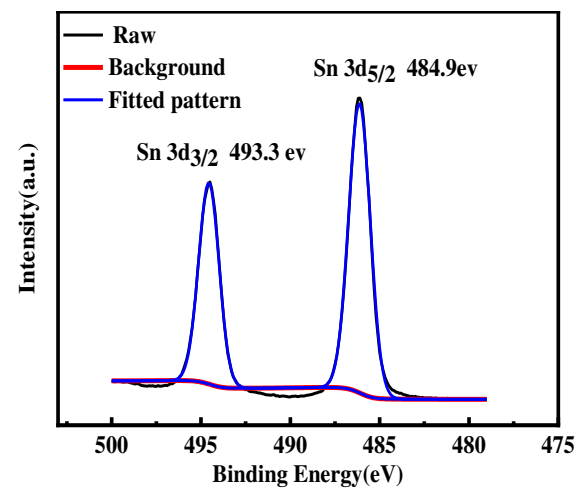

Fig. 3 a. The XPS of $\mathrm{Fe}_{2} \mathrm{O}_{3}, \mathrm{Fe}_{2} \mathrm{O}_{3} / \mathrm{C}$ (the mass ratio of 3:1), $\mathrm{Fe}_{2} \mathrm{O}_{3} / \mathrm{C} @ \mathrm{SnO}_{2}$ (the mass ratio of 3:1:4), b high-resolution curves of $\mathbf{c ~ F e}, \mathrm{Sn}$, and $\mathbf{d} \mathrm{C}$.

Furthermore, to explore the composition of the $\mathrm{Fe}_{2} \mathrm{O}_{3} / \mathrm{C}$ and $\mathrm{Fe}_{2} \mathrm{O}_{3} / \mathrm{C} @ \mathrm{SnO}_{2}$ nanostructure, the XPS technique was used. The full spectrum characteristic peaks composed of Fe 2p, C 1s, O 1s, and Sn 3d states, as displayed in Fig. 3a. The peaks at 712.2 and $725.6 \mathrm{eV}$ were ascribed to the $\mathrm{Fe} 2 \mathrm{p}_{3 / 2}$ and $\mathrm{Fe} 2 \mathrm{p}_{1 / 2}$, while the peak at 715.9 eV was attributed to $\mathrm{Sn} 3 \mathrm{p}_{3 / 2}{ }^{28}$. The $\mathrm{Fe}_{2} \mathrm{O}_{3} / \mathrm{C} @ \mathrm{SnO}_{2}$ sample shows the $\mathrm{Sn} 3 \mathrm{~d}_{3 / 2}$ and $\mathrm{Sn}$ $3 \mathrm{~d}_{5 / 2}$ around 493.3 and $4844.9 \mathrm{eV}$, with a spin-orbit splitting of $8.4 \mathrm{eV}$, which agree with the previously reported energy values for $\mathrm{SnO}_{2}{ }^{29}$. 
Sensing properties of the $\mathrm{Fe}_{2} \mathrm{O}_{3} / \mathrm{C} @ \mathrm{SnO}_{2}$ pressure sensor

a

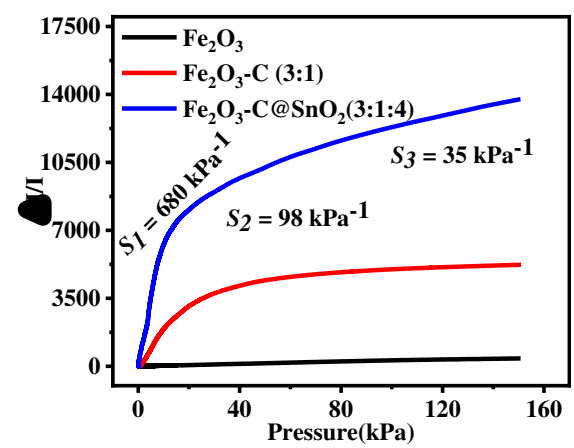

C

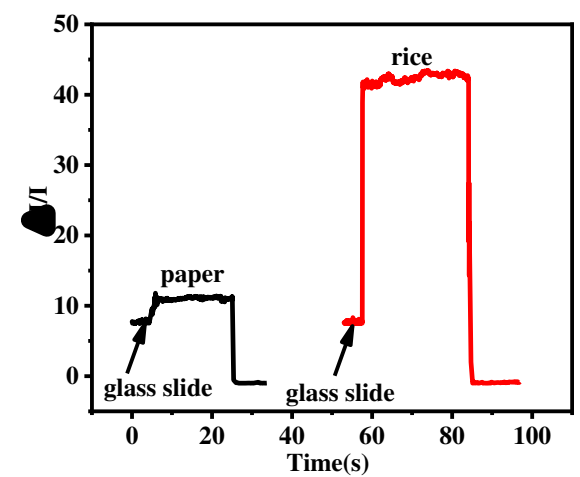

b

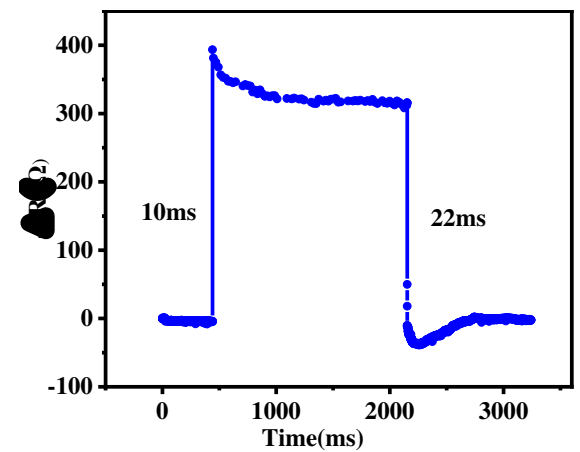

d

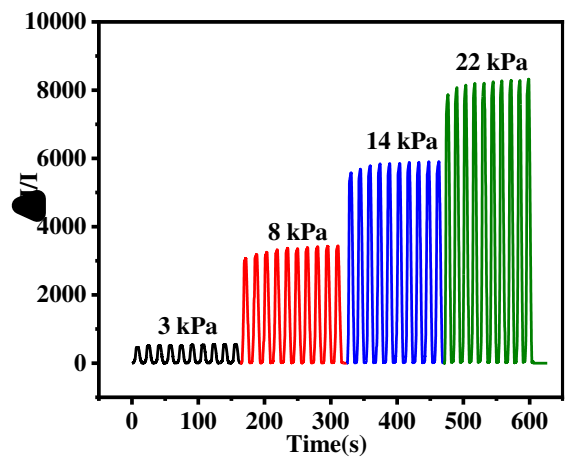

e

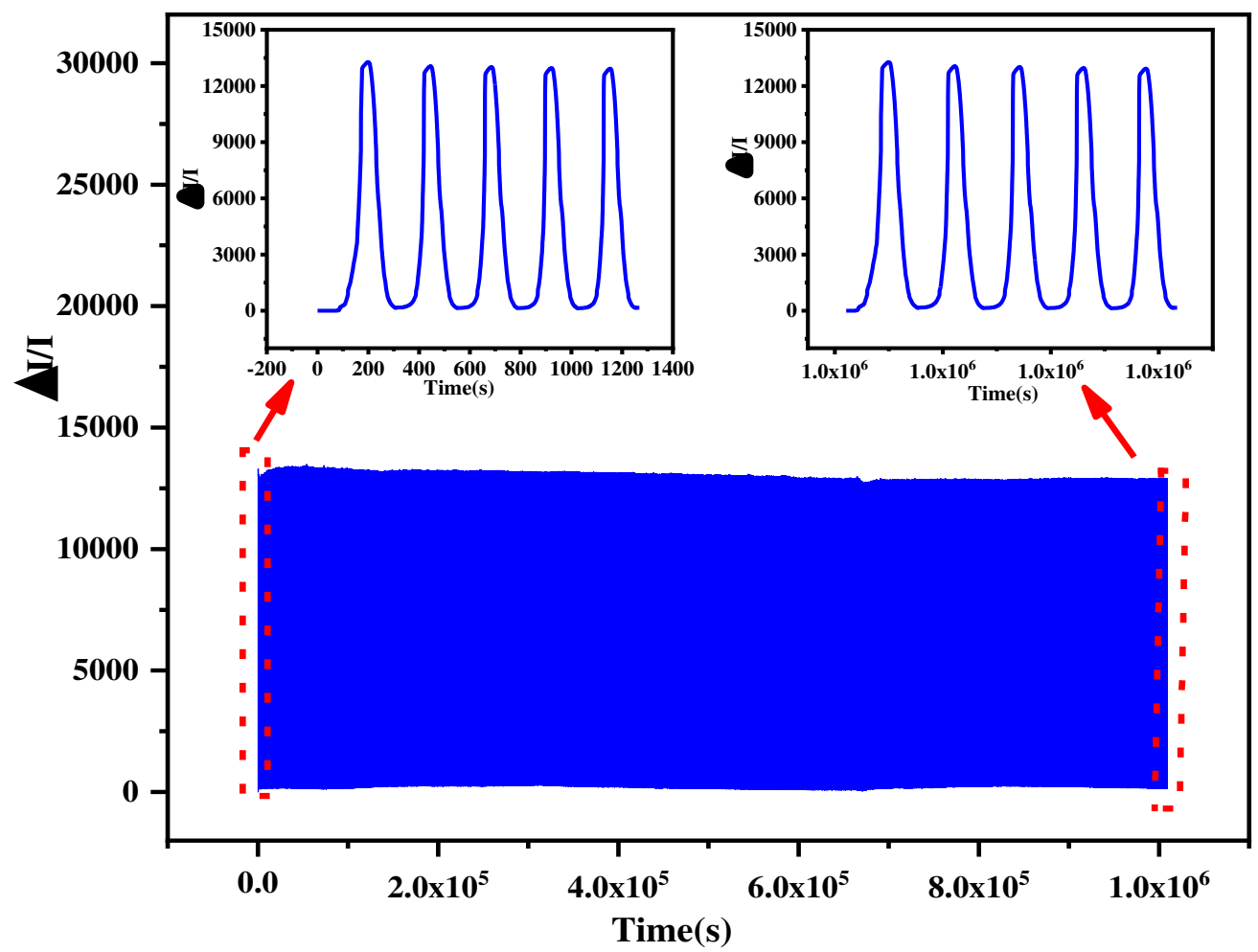

Fig. 4. a The sensitivity of $\mathrm{Fe}_{2} \mathrm{O}_{3}, \mathrm{Fe}_{2} \mathrm{O}_{3} / \mathrm{C}$ with the mass of ratio of (3:1), and $\mathrm{Fe}_{2} \mathrm{O}_{3} / \mathrm{C} @ \mathrm{SnO}_{2}$ with the mass of ratio of 3:1:4 based sensors. b Response time of $\mathrm{Fe}_{2} \mathrm{O}_{3} / \mathrm{C} @ \mathrm{SnO}_{2}(3: 1: 4)$ pressure sensor. c Detection of weak pressure: current curve of the proposed $\mathrm{Fe}_{2} \mathrm{O}_{3} / \mathrm{C} @ \mathrm{SnO}_{2}(3: 1: 4)$ pressure sensor pressed by paper and rice grain. $\mathbf{d}$ The current response due to increased pressures under loading and unloading. e Stability performance of the $\mathrm{Fe}_{2} \mathrm{O}_{3} / \mathrm{C} @ \mathrm{SnO}_{2}$ (3:1:4) pressure sensor with loadingunloading of more than 3500 cycles. 
To measure the piezoresistive characteristics of is pressure sensor, we set up a custom-made system composed of a universal testing machine and a digital source meter. The formula for calculating sensitivity was based on $S=\left(\Delta I / I_{\text {unloading }}\right) / \Delta p$, where $\Delta I=I$ loading- $I$ unloading, which refers to relative current change, while $\Delta p$ refers to the change of pressure. The measurement results are depicted in Fig. 4a, Fig. S3, and Table. S1. The sensitivity of $\mathrm{Fe}_{2} \mathrm{O}_{3} / \mathrm{C} @ \mathrm{SnO}_{2}$ pressure sensor was higher than that of $\mathrm{Fe}_{2} \mathrm{O}_{3}$, $\mathrm{Fe}_{2} \mathrm{O}_{3} / \mathrm{C}$, and $\mathrm{SnO}_{2} @ \mathrm{C}$ pressure sensors. The sensitivity of $\mathrm{Fe}_{2} \mathrm{O}_{3} / \mathrm{C} @ \mathrm{SnO}_{2}(3: 1: 4)$ sensors is $S_{1} \sim 680 \mathrm{kPa}^{-1}$ when the pressure is below $10 \mathrm{kPa}$, is $S_{2} \sim 98 \mathrm{kPa}^{-1}$ within the pressure range of $10-50 \mathrm{kPa}$, and is $S_{3} \sim 35 \mathrm{kPa}^{-1}$ within the pressure range of $50-$ $150 \mathrm{kPa}$. It is apparently higher than that of $\mathrm{ZnO}$ sea urchin-like, carbon sea urchin-like, $\mathrm{Ag} / \mathrm{Au}$ sea urchin-like, and other pressure sensors, as shown in Table S2. Although the sea urchin-like $\mathrm{Fe}_{2} \mathrm{O}_{3}$ structure promoted signal transduction and protected $\mathrm{Fe}_{2} \mathrm{O}_{3}$ needles against mechanical breakage, the sensitivity of the sensor $\left(3 \mathrm{kPa}^{-1}\right)$ was still lower, because $\mathrm{Fe}_{2} \mathrm{O}_{3}$ has poor conductivity. Also, the change in current was still smaller even under the effect of larger pressure. Fig. S3a and Table. S1 shows the current response of the pressure sensors under the different mass ratio of $\mathrm{Fe}_{2} \mathrm{O}_{3}$ and carbon, which indicates that the mass ratio of (3:1) has the highest sensitivity $\left(203 \mathrm{kPa}^{-1}\right)$ compared to the other lower ratios $(2: 1,1: 1$ and 1:2) and also the large one (4:1), let alone the pure carbon. A major reason for the high sensitivity of the $\mathrm{Fe}_{2} \mathrm{O}_{3} / \mathrm{C}$ pressure sensor can be explained as follows. On one hand, the microfibers of sponge are composed of nanocomposites so that the contact area is increased and thus leading to an increase of current, as viewed in Fig. S6. On the other hand, when adding carbon 
into the $\mathrm{Fe}_{2} \mathrm{O}_{3}$ system, the $\mathrm{Fe}_{2} \mathrm{O}_{3} / \mathrm{C}$ nanocomposite exhibits a larger current variation compared to that of pure carbon. Under the constant mass of $\mathrm{Fe}_{2} \mathrm{O}_{3}$, followed with increased amounts of carbon, the sensitivity of the $\mathrm{Fe}_{2} \mathrm{O}_{3} / \mathrm{C}$ pressure sensor increases due to the increase of the conductive path. However, the excess addition of carbon to the sensor may significantly increase conductivity (when the mass ratio of carbon and $\mathrm{Fe}_{2} \mathrm{O}_{3}$ exceeds 1:3) and thus making it become a good conductor, but in return affecting its further increase of corresponding conductive pathways. Here, we noted that the addition of carbon greatly improves the sensitivity of the sensor in the pressure range (within $50 \mathrm{kPa}$ ), but does not obviously improve the sensitivity in the pressure range (over $50 \mathrm{kPa}$ ), as displayed in Fig. S3a.

To improve the sensitivity of the pressure sensor under the high-pressure range (over $50 \mathrm{kPa}$ ), $\mathrm{Fe}_{2} \mathrm{O}_{3} / \mathrm{C}(3: 1)$ was further combined with $\mathrm{SnO}_{2}$. The addition of $\mathrm{SnO}_{2}$ nanoparticles not only improves the sensitivity of the sensor in the low-pressure range (within $50 \mathrm{kPa}$ ) but also improves its sensitivity in the pressure range (over $50 \mathrm{kPa}$ ) (Fig. S3b and Table S1). Furthermore, when the two semiconductors were brought in contact and subjected to high-temperature calcination, the hand alignment occurred driven by the equilibration of the Fermi level as shown in Fig. S4 ${ }^{30,31}$. Consequently, an n-n type heterostructure was formed between $\mathrm{Fe}_{2} \mathrm{O}_{3}$ and $\mathrm{SnO}_{2}$, which promotes the transfer of electrons from $\mathrm{Fe}_{2} \mathrm{O}_{3}$ to $\mathrm{SnO}_{2}$, thus enhancing the conductivity of the pressure sensor. Besides, Fig. S2i show that the $\mathrm{SnO}_{2}$ nanoparticles grew on the (104) surface of the $\mathrm{Fe}_{2} \mathrm{O}_{3}$, along the direction of (110) $\mathrm{SnO}_{2}$, and thereby forming (104) $\mathrm{Fe} 2 \mathrm{O} /$ (110) $\mathrm{SnO} 2$ heterojunction. Collectively, the synergy of the three structures $\left(\mathrm{Fe}_{2} \mathrm{O}_{3} / \mathrm{C}\right.$, 
$\mathrm{Fe}_{2} \mathrm{O}_{3} / \mathrm{SnO}_{2}$ and $\mathrm{SnO}_{2} @ \mathrm{C}$ ) improved the limited pressure response range of a single structure. Of note, the content of $\mathrm{SnO}_{2}$ in $\mathrm{Fe}_{2} \mathrm{O}_{3} / \mathrm{C} @ \mathrm{SnO}_{2}$ exhibited a significant role in sensing the performance of the pressure sensor as elucidated in Fig. S3b. In addition, when more $\mathrm{SnO}_{2}\left(\mathrm{Fe}_{2} \mathrm{O}_{3} / \mathrm{C} @ \mathrm{SnO}_{2}(3: 1: 8)\right)$ was added in the synthesis, the polymerization of $\mathrm{SnO}_{2}$ nanoparticles occurred due to their high surface energy, and subsequently leading to a non-uniformed distribution of $\mathrm{SnO}_{2}$ nanoparticles in $\mathrm{Fe}_{2} \mathrm{O}_{3} / \mathrm{C} @ \mathrm{SnO}_{2}$. Conversely, when less $\mathrm{SnO}_{2}\left(\mathrm{Fe}_{2} \mathrm{O}_{3} / \mathrm{C} @ \mathrm{SnO}_{2}(3: 1: 1)\right)$ was added in the synthesis, less "accumulation layer" was formed on $\mathrm{SnO}_{2}$. It affected the conductivity of the pressure sensor. Therefore, the obtained $\mathrm{Fe}_{2} \mathrm{O}_{3} / \mathrm{C} @ \mathrm{SnO}_{2}(3: 1: 8)$ and $\mathrm{Fe}_{2} \mathrm{O}_{3} / \mathrm{C} @ \mathrm{SnO}_{2}(3: 1: 1)$ deemed lower sensitivity compared with $\mathrm{Fe}_{2} \mathrm{O}_{3} / \mathrm{C} @ \mathrm{SnO}_{2}(3: 1: 4)$. Besides, $\mathrm{Fe}_{2} \mathrm{O}_{3} / \mathrm{C} @ \mathrm{Sb}_{2} \mathrm{O}_{3}(3: 1: 4)$ was synthesized and characterized to verify whether the ternary structure has a certain universality in improving the sensitivity and expanding the pressure working range of the piezoresistive pressure sensor. The sensitivity of $\mathrm{Fe}_{2} \mathrm{O}_{3} / \mathrm{C} @ \mathrm{Sb}_{2} \mathrm{O}_{3}(3: 1: 4)$ sensors is $S_{1} \sim 303 \mathrm{kPa}^{-1}$ when the pressure is below $10 \mathrm{kPa}$, is $S_{2} \sim 41 \mathrm{kPa}^{-1}$ within the pressure range of $10-50 \mathrm{kPa}$, and is $S_{3} \sim 13$ $\mathrm{kPa}^{-1}$ within the pressure range of $50-150 \mathrm{kPa}$ as shown in Fig. S5. The experimental result showed that the ternary structure has a certain universality in improving the sensitivity and expanding the pressure working range of the piezoresistive pressure sensor.

Besides, we further assessed the low limit detection of the $\mathrm{Fe}_{2} \mathrm{O}_{3} / \mathrm{C} @ \mathrm{SnO}_{2}(3: 1: 4)$ pressure sensor as outlined in Fig. 4c. To evaluate the low limit detection of the sensor, a weight of $4.2 \mathrm{~g}$ glass slide was placed on the pressure sensor. Thereafter, a paper $(\sim$ 
$\left.0.52 \mathrm{pa}, m=0.0107 \mathrm{~g}, S=1 \times 2 \mathrm{~cm}^{2}\right)$ and rice $(m=0.0116)$ were put on the glass slide. The glass slide served two purposes including (1) completing the contact between the electrode and the sensor, and (2) making the current more stable. Moreover, the response time of the $\mathrm{Fe}_{2} \mathrm{O}_{3} / \mathrm{C} @ \mathrm{SnO}_{2}$ (3:1:4) pressure sensor is depicted in Fig. 4b. Compressing the sponge pressure sensor by $0.02 \mathrm{~mm}$ at a speed of $500 \mathrm{~mm} / \mathrm{min}$, the response time and recovery time of the $\mathrm{Fe}_{2} \mathrm{O}_{3} / \mathrm{C} @ \mathrm{SnO}_{2}(3: 1: 4)$ pressure sensor was 10 and $22 \mathrm{~ms}$, respectively. Hence, the hysteresis of the recovery time of this pressure sensor may be mainly attributed to the sponge substrate. To evaluate the stability of the pressure sensor under the different pressures, the $\mathrm{Fe}_{2} \mathrm{O}_{3} / \mathrm{C} @ \mathrm{SnO}_{2}(3: 1: 4)$ pressure sensor was set under various pressure values of 3, 8, 14 and $22 \mathrm{kPa}$ as illustrated in Fig. $4 \mathrm{~d}$. The findings revealed that the current gradually increases with increasing pressure. Therefore, suggesting that $\mathrm{Fe}_{2} \mathrm{O}_{3} / \mathrm{C} @ \mathrm{SnO}_{2}$ (3:1:4) pressure sensor can clearly distinguish the pressure of different levels. Furthermore, repeated compression/release test over 3500 cycles with a peak pressure of $110 \mathrm{kPa}$ was performed (Fig. 4e). The insets revealed the 5 cycles of the current response at the inception (left) and termination (right) of the stability test, whereas, the sensor indicated a stable signal without offset during the cycles test, and thereby reflecting that the performance of the sensor is still stable under long cycles and high pressure. The SEM images of sponge in the original state and compression/release over 3500 cycles state are displayed in Fig. S2g-h. Compared with the original state, the micromorphology of $\mathrm{Fe}_{2} \mathrm{O}_{3}$ exhibited no change when the sensor was repeatedly compressed/released under the high pressure. However, only a small part of the $\mathrm{Fe}_{2} \mathrm{O}_{3}$ needles was detached from the sea urchin- 
shaped microspheres. In this work, the good stability of the sensor could be attributed to two reasons namely (1) the tapering geometry of $\mathrm{Fe}_{2} \mathrm{O}_{3}$ protects the bristle from mechanical breaking ${ }^{21,22}$, and (2) there is a lot of space between the $\mathrm{Fe}_{2} \mathrm{O}_{3}$ needle, which can allow carbon and $\mathrm{SnO}_{2}$ nanoparticles to easily absorb onto the interval gap, and hence protecting the integrity of the $\mathrm{Fe}_{2} \mathrm{O}_{3}$ needle structure.

\section{Extremely high-pressure resolution}

a

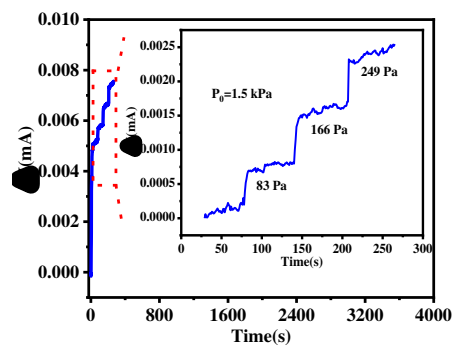

d

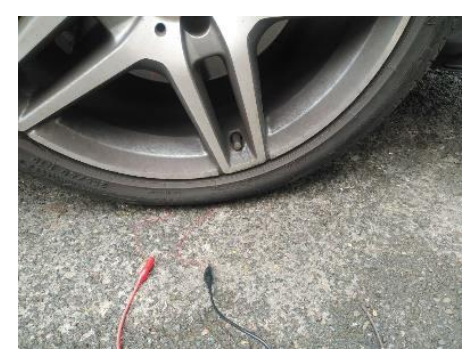

b

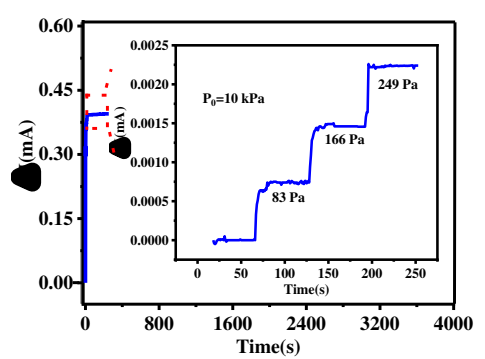

e

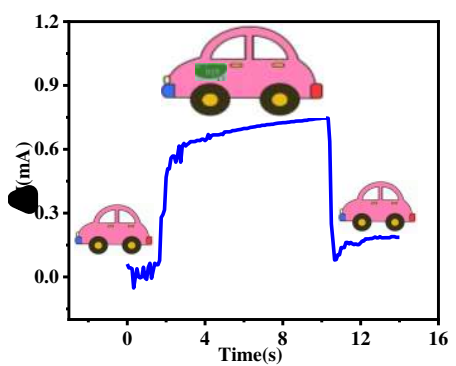

c

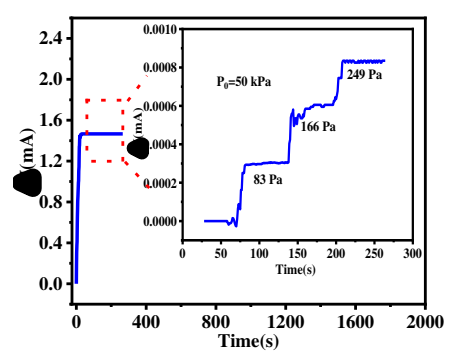

f

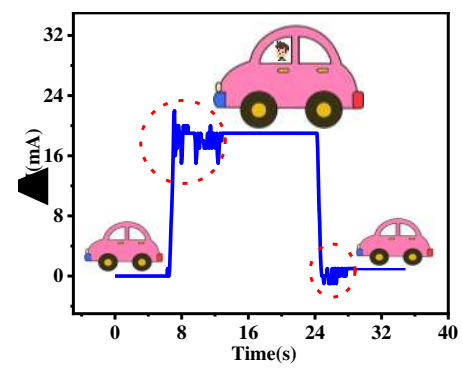

Fig. 5. Detection of micro pressure under loading pressures of a $1.5 \mathrm{kPa}, \mathbf{b} 10 \mathrm{kPa}$, and $\mathbf{c} 50 \mathrm{kPa}$. d Experimental set-up of a car with a $\mathrm{Fe}_{2} \mathrm{O}_{3} / \mathrm{C} @ \mathrm{SnO}_{2}$ (3:1:4) pressure sensor attached under a front tire. e Current signals corresponding to an unloaded, loaded, and unloaded $4 \mathrm{~kg}$ carton of milk on the driving seat of the car. $\mathbf{f}$ Current signals corresponding to a $73 \mathrm{~kg}$ male passenger getting into and out of the car.

The key feature of the $\mathrm{Fe}_{2} \mathrm{O}_{3} / \mathrm{C} @ \mathrm{SnO}_{2}(3: 1: 4)$ pressure sensor is high sensitivity in a wide pressure range. In this respect, to evaluate the sensitivity of this sensor under high pressure, it was tested as follows. Specifically, the pressure sensor was subject to different pressure values at 1.5, 10 and $50 \mathrm{kPa}$, as illustrated in Fig. 5a-c. First, the sensor was compressed to the set pressure value, followed by consecutive addition of 
three coins, each weighing about $3.19 \mathrm{~g}$, which is equivalent to a pressure of $86 \mathrm{~Pa}$. Each pressure increment caused a step increase of current, and the current signal is stable. In another experiment, a pressure sensor with a volume of $V=19 \times 19 \times 4 \mathrm{~mm}^{3}$ was placed under the front wheel of a car (the weight of the car is $1670 \mathrm{~kg}$ ) as shown in Fig. 5d. Thereafter, a carton of milk weighing $4 \mathrm{~kg}$ put on the driving seat of the car and then taken away as indicated in Fig. 5e. Consequently, the changes in current were successfully detected. Likewise, when the male passenger with a weight of $73 \mathrm{~kg}$ gets into or out of the car, the current changed significantly (Fig. 5f). The circled vibrations in Fig. $5 \mathrm{f}$ demonstrated that the sensor can accurately capture the movement of the male passenger getting on or off the car. It shows that the sensor still has high sensitivity under the high pressure.

\section{Wearable device demonstration}

a

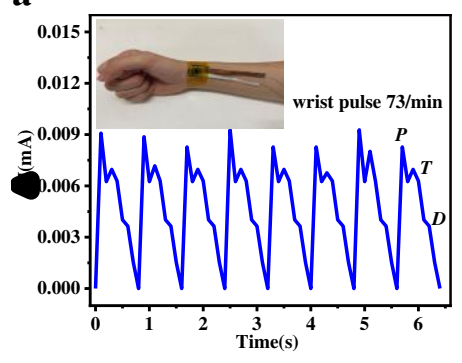

d

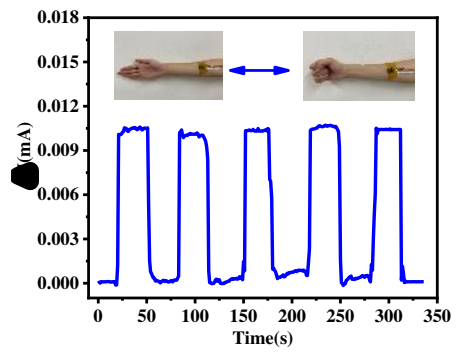

b

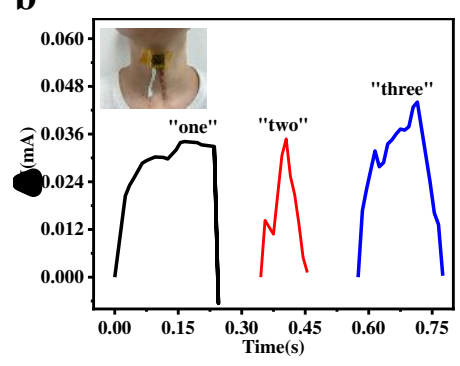

e

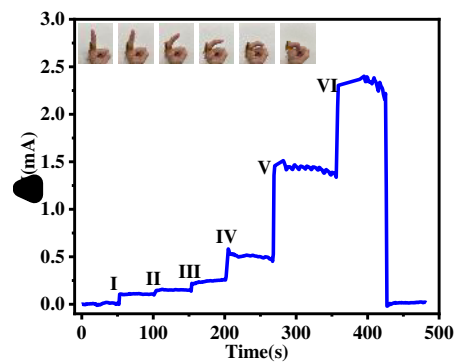

c

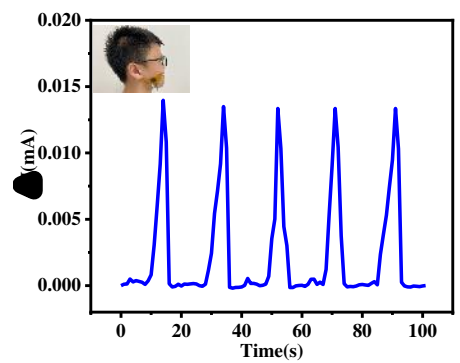

f

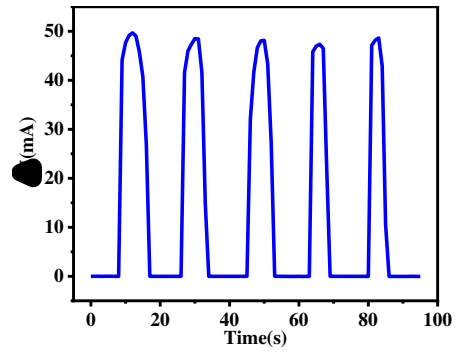

Fig. 6. a The current response caused by the arterial pulse waves with the sensor attached to the wrist. b The recorded current signal versus time pronouncing. Finally, $\mathbf{c}$ the signal variations of relative current corresponding to different occlusion, $\mathbf{d}$ human palm, $\mathbf{e}$ finger motion, and $\mathbf{f}$ walking. 
Due to the high sensitivity, faster response, and broad pressure regime of the sensor $\left(\mathrm{Fe}_{2} \mathrm{O}_{3} / \mathrm{C} @ \mathrm{SnO}_{2}(3: 1: 4)\right)$, it can thus be applied in many fields. For instance, it can be used to detect voice, wrist pulse, and human motion activities. Fig. 6a shows the realtime wrist pulse detecting using the $\mathrm{Fe}_{2} \mathrm{O}_{3} / \mathrm{C} @ \mathrm{SnO}_{2}$ (3:1:4) pressure sensor. The testing curves revealed strong characteristic peaks of the human sphygmic waveforms, and the pulse rate at about 73 times/min, which is the normal level. Notably, based on the excellent performance of the $\mathrm{Fe}_{2} \mathrm{O}_{3} / \mathrm{C} @ \mathrm{SnO}_{2}(3: 1: 4)$ pressure sensor, it can be used for monitoring human health. Subsequently, this pressure sensor was attached to the human throat to monitor and distinguish subtle differences during the muscle motions near the throat, when the words "one", "two" and "three" were spoken as shown in Fig. 6b. Interestingly, this technique can be applied to deaf and mute people who are unable to speak. It is well-known that their vocal cords can vibrate, and thus vibration produced can be transformed into the required sound ${ }^{7}$. Moreover, the pressure sensor was mounted on the cheek to monitor the occlusion movement of humans as displayed in Fig. 6c. Upon occlusion, the current changed significantly, which once again proves the excellent performance of the sensor. Also, the pressure sensor was attached to the arm to detect the radial muscle contraction, which occurs when making a fist as viewed in Fig. 6d. When the tester made a fist, the current signal increased as well as the compression of the sensor. Therefore, this result illustrates its valuable potential application in physical training and curing muscle damage. The response of the sensor for continuously bending six different motions of the finger is elucidated in Fig. 6e. Consequently, it was noted that the sensor showed different responsive current signals 
to different motions of the finger. In particular, the current signal exhibited a slight increase when the finger bent in small-scale (motion-I, motion-II, and motion-III), whereas larger-scale bending led to the sharp increase of current value (motion-IV, motion-V, and motion-VI). The large-scale movements resulted in a strong compression of the sensor and thus forming more conductive pathways. These findings demonstrated that the pressure sensor can precisely distinguish different-scale motions of the finger. In addition, Fig. $6 \mathrm{f}$ shows the pressure sensor mounted on foot using tape to monitor walking states. The response signals of walking motion were stable and repetitive. This suggests that it can be applied for gait recognition and motion monitoring. Conclusively, these outcomes enumerate that the $\mathrm{Fe}_{2} \mathrm{O}_{3} / \mathrm{C} @ \mathrm{SnO}_{2}$ pressure sensor holds broad application prospects in the fields of medical health and wearable electronic devices.

\section{Conclusion}

In summary, we present a sea urchin-shaped microstructure $\mathrm{Fe}_{2} \mathrm{O}_{3} / \mathrm{C} @ \mathrm{SnO}_{2}$, which was synthesized using a simple and environmentally friendly hydrothermal method. We also provide a pressure sensor with high sensitivity and a large working range based on a simple dip-coating process method. Notably, the $\mathrm{Fe}_{2} \mathrm{O}_{3} / \mathrm{C} @ \mathrm{SnO}_{2}$ pressure sensor exhibits high sensitivity $\left(680 \mathrm{kPa}^{-1}\right)$, fast response $(10 \mathrm{~ms})$, broad range (up to $150 \mathrm{kPa}$ ), and good reproducibility (over 3500 cycles under a pressure of 110 $\mathrm{kPa}$ ). Interestingly, multiple human physiological activities (such as pulse, pronouncing, joint bending, and walking, among others) could be monitored using the $\mathrm{Fe}_{2} \mathrm{O}_{3} / \mathrm{C} @ \mathrm{SnO}_{2}$ pressure sensor. Lastly, based on the above excellent performance of the device, it has significant implications especially in wearable electronics, health 
monitoring, and measuring pressure distribution.

\section{Experimental}

\section{Synthesis of $\mathrm{Fe}_{2} \mathrm{O}_{3}$}

The detailed processing method for the synthesis of $\mathrm{Fe}_{2} \mathrm{O}_{3}$ used in this study can be found in one of the authors' previous works ${ }^{32}$. In particular, the $\mathrm{Fe}_{2} \mathrm{O}_{3}$ was synthesized through a hydrothermal process, where $0.405 \mathrm{~g} \mathrm{FeCl}_{3} \cdot 6 \mathrm{H}_{2} \mathrm{O}$ and $0.205 \mathrm{~g}$ $\mathrm{Na}_{2} \mathrm{SO}_{4}$ were first dissolved in distilled water $(30 \mathrm{~mL})$ and stirred for $10 \mathrm{~min}$. Afterward, the mixture was heated at $120^{\circ} \mathrm{C}$ for $6 \mathrm{~h}$ in a Teflon-lined stainless-steel autoclave. Lastly, after cooling, filtering, drying, and thermal annealing at $400{ }^{\circ} \mathrm{C}$ for $3 \mathrm{~h}$ under air, $\mathrm{Fe}_{2} \mathrm{O}_{3}$ was obtained.

\section{Preparation of $\mathrm{Fe}_{2} \mathrm{O}_{3} / \mathrm{C}$ composites}

Besides adding different masses of carbon, the same process was used for the synthesis of $\mathrm{Fe}_{2} \mathrm{O}_{3} / \mathrm{C}$ composites.

\section{Synthesis of $\mathrm{Fe}_{2} \mathrm{O}_{3} / \mathrm{C} / \mathrm{SnO}_{2}$ composites}

First, $\mathrm{Fe}_{2} \mathrm{O}_{3} / \mathrm{C}$ composite $(0.145 \mathrm{~g}), \mathrm{Na}_{2} \mathrm{SnO}_{3}(0.145 \mathrm{~g}, 0.036 \mathrm{~g}, 0.290 \mathrm{~g})$ and urea (1.16 g, $0.290 \mathrm{~g}, 2.320 \mathrm{~g}$ ) was dissolved in ethanol/ $\mathrm{H}_{2} \mathrm{O}$ solution and kept $\mathrm{V}_{\text {ethanol: }}$ $\mathrm{V}_{\mathrm{H} 2 \mathrm{O}}=2: 3$. Subsequently, after stirring for $15 \mathrm{~min}$, the mixture was heated at $180{ }^{\circ} \mathrm{C}$ for 6h in a Teflon-lined stainless-steel autoclave. Next, after cooling naturally in air, the $\mathrm{Fe}_{2} \mathrm{O}_{3} / \mathrm{C} @ \mathrm{SnO}_{2}$ composites were washed several times with distilled water and absolute ethanol. Finally, the $\mathrm{Fe}_{2} \mathrm{O}_{3} / \mathrm{C} @ \mathrm{SnO}_{2}$ composites were dried at $60{ }^{\circ} \mathrm{C}$ for $12 \mathrm{~h}$.

\section{Preparation of conductive sponges and electrode}

Melamine sponge was cut into a cuboid with a length of $19 \mathrm{~mm}$, width $(19 \mathrm{~mm})$, 
and height $(4 \mathrm{~mm})$. Then it was the melamine sponge was washed several times with ethanol and dried at $45^{\circ} \mathrm{C}$. Thereafter, $\mathrm{Fe}_{2} \mathrm{O}_{3} / \mathrm{C} @ \mathrm{SnO}_{2}\left(\mathrm{SnO}_{2} @ \mathrm{C}, \mathrm{Fe}_{2} \mathrm{O}_{3} / \mathrm{C}, \mathrm{Fe}_{2} \mathrm{O}_{3}\right.$, $\mathrm{SnO}_{2}$, and $\mathrm{C}$ ) and Polyvinylidene fluoride (PVDF) binder were dissolved in N-methyl pyrrolidone (NMP) in a weight ratio of 10:1 and mixed to form a slurry. Next, the melamine sponge strip was immersed in slurry until full and dried at $45^{\circ} \mathbf{C}$ in a vacuum. The copper wire was soldered on the copper tape with a size of $19 \mathrm{~mm} \times 19 \mathrm{~mm}$ while the sponge was sandwiched between two copper tape.

\section{Characterization of structures and performance of the sensors}

The crystal structures of the samples were explored using X-ray diffraction (XRD, PANalytical X'Pert Powder), whereas, the morphology was characterized using scanning electron microscopy (SEM; Quattro S), high-angle annular dark-field scanning transmission electron microscopy (HAADF-STEM), elemental mapping and transmission electron microscopy (TEM; Talos F200S). The binding energy of products was investigated using X-ray photoelectron spectroscopy (XPS; ESCALAB250Xi). Moreover, the loading of pressure was examined using a universal testing machine (ETM-5038, Shenzhen Wance Testing Machine Co., Ltd.), while the electrical signals of the pressure sensors were recorded at the same time using a Keithley 2450 digital meter at a constant voltage of $0.1 \mathrm{~V}$. Finally, to assess the response time of the pressure sensor, a Keithley DAQ6510 multimeter was used. 


\section{Reference}

1. Shin, M. K., Oh, J., Lima, M., Kozlov, M. E., Kim, S. J., \& Baughman, R. H. Elastomeric conductive composites based on carbon nanotube forests. Advanced Materials, 22(24), 2663-2667 (2010).

2. Jian, M., et al. Flexible and highly sensitive pressure sensors based on bionic hierarchical structures. Advanced Functional Materials, 27(9), 160666(2017).

3. Zhou, Z., Li, Y., Cheng, J., Chen, S., \& Li, L. Supersensitive all-fabric pressure sensors using printed textile electrode arrays for human motion monitoring and human-machine interaction. Journal of Materials Chemistry C, 6(48), 1312013127 (2018).

4. Schwartz, G. et al. Flexible polymer transistors with high pressure sensitivity for application in electronic skin and health monitoring. Nature Communications, 4, 1859 (2013).

5. Bai, N., Wang, L., Wang, Q., Deng, J., \& Guo, C. F. Graded intrafillable architecturebased iontronic pressure sensor with ultra-broad-range high sensitivity. Nature Communications, 11(1), 209 (2020).

6. Cho, S. H. et al. Micropatterned pyramidal ionic gels for sensing broad-range pressures with high sensitivity. Acs Applied Materials \& Interfaces, 9(11), 1012810135 (2017).

7. Mannsfeld, S. C. et al. Highly sensitive flexible pressure sensors with microstructured rubber dielectric layers. Nature Materials, 9(10), 859-864 (2010).

8. Pang, Y. et al. A flexible highly sensitive and wearable pressure and strain sensors with graphene porous network structure. Acs Applied Materials \& Interfaces, 22374-22381(2016).

9. Maheshwari, V., \& Saraf, R. High-resolution thin-film device to sense texture by touch. Science, 312(5779), 1501-1504(2006).

10. Lou, Z., Chen, S., Wang, L., Jiang. K., \& Shen, G. An ultra-sensitive and rapid response speed graphene pressure sensor for electronic skin and health monitoring. Nano Energy, 7-14(2016).

11. Sun, J. et al. Piezo-phototronic effect improved performance of n -Zno nano-arrays/ p - $\mathrm{Cu}_{2} \mathrm{O}$ film based pressure sensor synthesized on flexible cu foil. Nano Energy, 32, 96-104(2016).

12. Wen, zhuo. et al. Taxel-addressable matrix of vertical-nanowire piezotronic transistors for active and adaptive tactile imaging. Science, 340(6135):952957(2013).

13. Sumin. et al. Transparent and stretchable interactive human machine interface based on patterned graphene heterostructures. Advanced Functional Materials, 25,375(2015).

14. Khan, U. et al. Graphene tribotronics: graphene tribotronics for electronic skin and touch screen applications. Advanced Materials, 29, 1603544(2017).

15. Wang, X., et al. Self-powered high-resolution and pressure-sensitive triboelectric sensor matrix for real-time tactile mapping. Advanced Materials, 28(15), 28962903(2016). 
16. Su, Y., Chen, J., Wu, Z., \& Jiang, Y. Low temperature dependence of triboelectric effect for energy harvesting and self-powered active sensing. Applied Physics Letters, 106(1), 3788(2015).

17. Pang, C. et al. A flexible and highly sensitive strain-gauge sensor using reversible interlocking of nanofibres. Nature Materials, 11(9), 795-801(2012).

18. Pan, L. et al. An ultra-sensitive resistive pressure sensor based on hollow-sphere microstructure induced elasticity in conducting polymer film. Nature Communications, 5,3002(2014).

19. Choong, C. L. et al. Highly stretchable resistive pressure sensors using a conductive elastomeric composite on a micropyramid array. Advanced Materials, 26(21), 3451-3458(2014).

20. Chen X. P. et al. A dual-functional graphene-based self-alarm health-monitoring eskin. Advanced Functional Materials, 29(51) (2019).

21. H.E. Dechant, F. Rammerstorfer, \& F. Barth. Arthropod touch reception: stimulus transformation and finite element model of spider tactile hairs., 187(10), 851851(2001).

22. Barth, F. G. Spider mechanoreceptors. Current Opinion in Neurobiology, 14(4), 415-422 (2004).

23. Yin, B., Liu, X., Gao, H., Fu, T., \& Yao, J. Bioinspired and bristled microparticles for ultrasensitive pressure and strain sensors. Nature Communications, 9(1),5161(2018).

24. Lee, D. et al. Highly sensitive, transparent, and durable pressure sensors based on sea-urchin shaped metal nanoparticles. Advanced Materials. 28, 9364-9369(2016).

25. Shi, L. et al. Quantum effect-based flexible and transparent pressure sensors with ultrahigh sensitivity and sensing density. Nature Communications, 11(1),3529(2020).

26. Xiang, Q., Yu, J., \& Jaroniec, M. Synergetic effect of $\mathrm{MoS}_{2}$ and graphene as cocatalysts for enhanced photocatalytic $\mathrm{H}_{2}$ production activity of $\mathrm{TiO}_{2}$ nanoparticles. Journal of the American Chemical Society, 134(15), 65756578(2012).

27. Lin, J. et al. Graphene nanoribbon and nanostructured $\mathrm{SnO}_{2}$ composite anodes for lithium ion batteries. Acs Nano, 7(7), 6001-6 (2013).

28. Wang, B. B. et al. Fabrication and gas sensing properties of hollow core-shell $\mathrm{SnO}_{2} / \alpha-\mathrm{Fe}_{2} \mathrm{O}_{3}$. heterogeneous structures. Journal of Alloys \& Compounds, 587, 82-89(2014).

29. Tian, Q., Li, L., Chen, J., Yang, L., \& Hirano, S. I. Facile fabrication of robust $\mathrm{TiO}_{2} @ \mathrm{SnO}_{2} @ \mathrm{C}$ hollow nanobelts for outstanding lithium storage. Journal of Power Sources, 376(1), 1-10 (2018).

30. Zhou. X. et al. Ordered porous metal oxide semiconductors for gas sensing. Chinese Chemical Letters, 29, 405 (2018).

31. Zhao, T. et al. Hierarchical branched mesoporous $\mathrm{TiO}_{2}-\mathrm{SnO}_{2}$ nanocomposites with well-defined $\mathrm{n}-\mathrm{n}$ heterojunctions for highly efficient ethanol sensing. Advanced Science, 6,02008(2019). 
32. Wang, X. M. et al. Excellent cyclic performance of $\mathrm{Fe}_{2} \mathrm{O}_{3} @ \mathrm{C} / \mathrm{SnO}_{2}$ controlled by $\mathrm{Fe}_{2} \mathrm{O}_{3} @ \mathrm{C}$ and $\mathrm{SnO}_{2} / \mathrm{C}$ hybrid structures for lithium-ion batteries. Journal of Physics \& Chemistry of Solids, 132,130-137(2019). 


\section{Acknowledgements}

This research was supported in part by the National Key Research and Development Program under Grant 2018YFB2100100, in part by the Pre-Research Project for 13th Five-Year Plan under Grant 614041404, in part by the China Postdoctoral Science Foundation under Grant 2019M663433, in part by the National Natural Science Foundation of China under Grant 61901064, in part by the Fundamental Research Funds for Central Universities under Grant 2019CDXYDQ0009, Grant 2019CDXYGD0028, Grant 106112017CDJQJ128836, Grant 2019CDQYDQ024, and Grant 2019CDJGFGD007, in part by the Key Science and Technology Program of Chongqing under Grant CSTC2017SHMS-ZDYFX0028, and in part by the Technology Innovation and Application Project of Chongqing under Grant CSTC2018JSZX-CYZD0587.

\section{Competing interests}

The authors declare no competing interests.

\section{Supplementary information}

Supplementary data associated with this paper about the experiment section and related details can be found in the online vision. 


\section{Figures}



Figure 1

Schematic illustration of the fabrication pressure sensor 

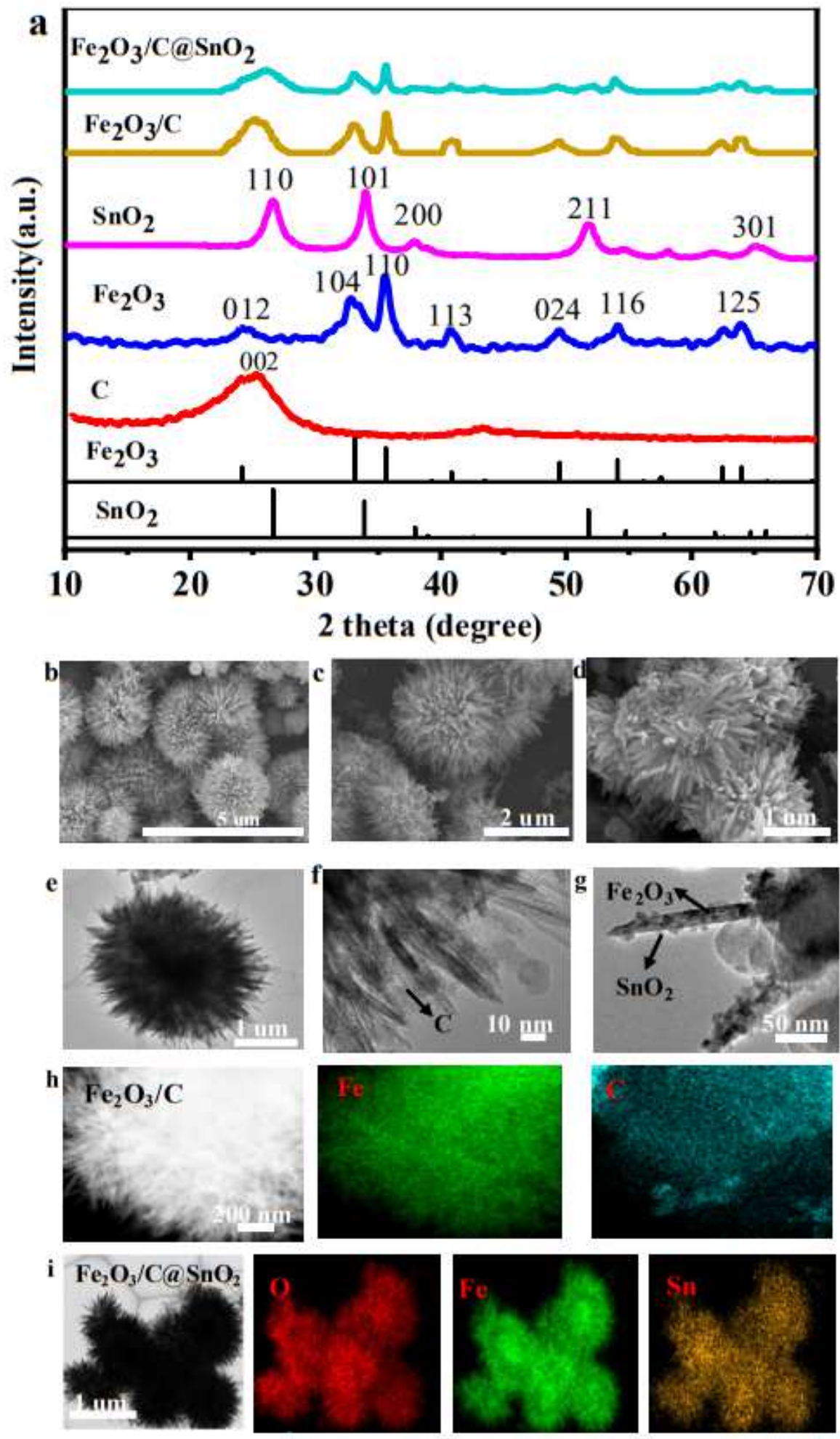

Figure 2

a The XRD patterns of acetylene carbon black, Fe2O3, SnO2, Fe2O3/C (3:1) and Fe2O3/C@SnO2 (3:1:4). SEM images of b Fe2O3, c Fe2O3/C (3:1), and d Fe2O3/C@SnO2 (3:1:4), TEM images of e Fe2O3, $f$ Fe2O3/C (3:1), and g Fe2O3/C@SnO2 (3:1:4), elemental mapping of h Fe2O3/C (3:1), and i Fe203/C@Sn02(3:1:4). 
$\mathbf{a}$

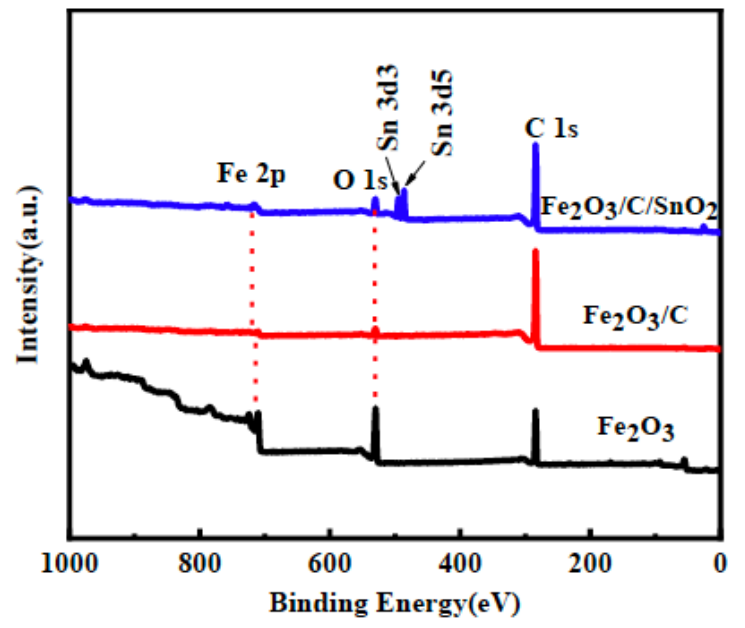

c

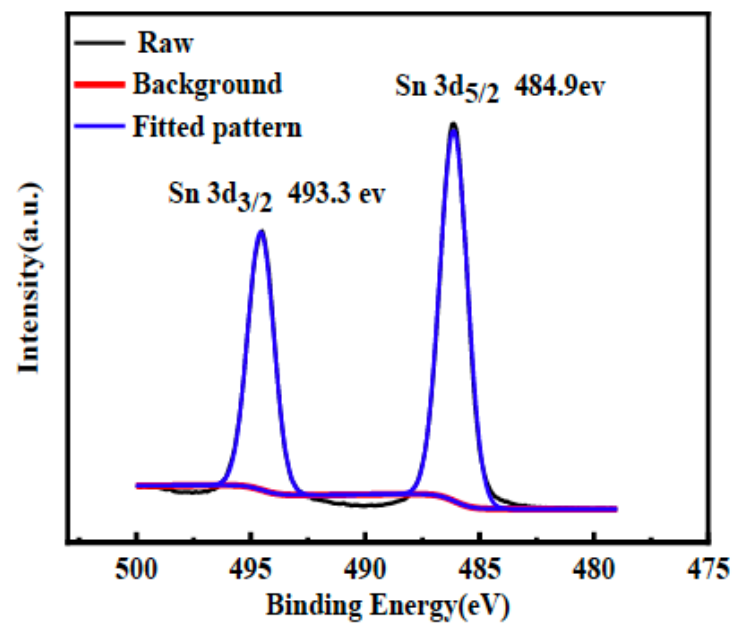

b

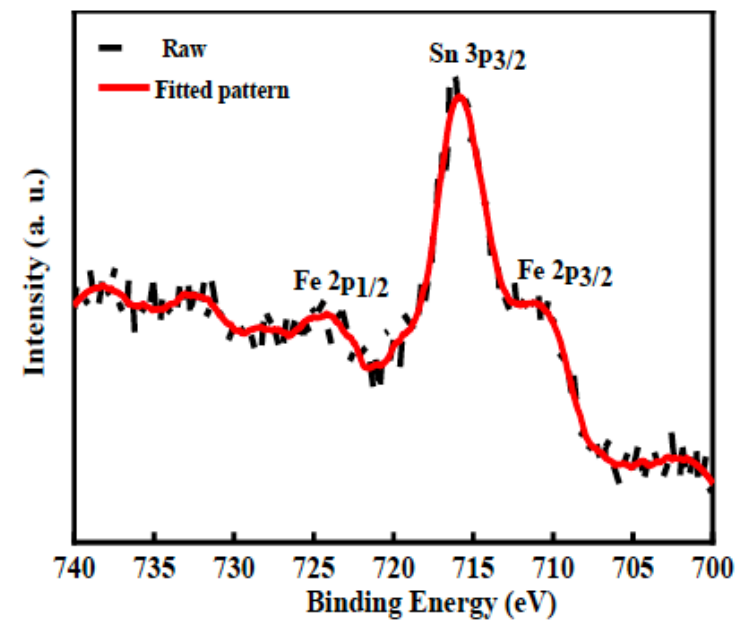

d

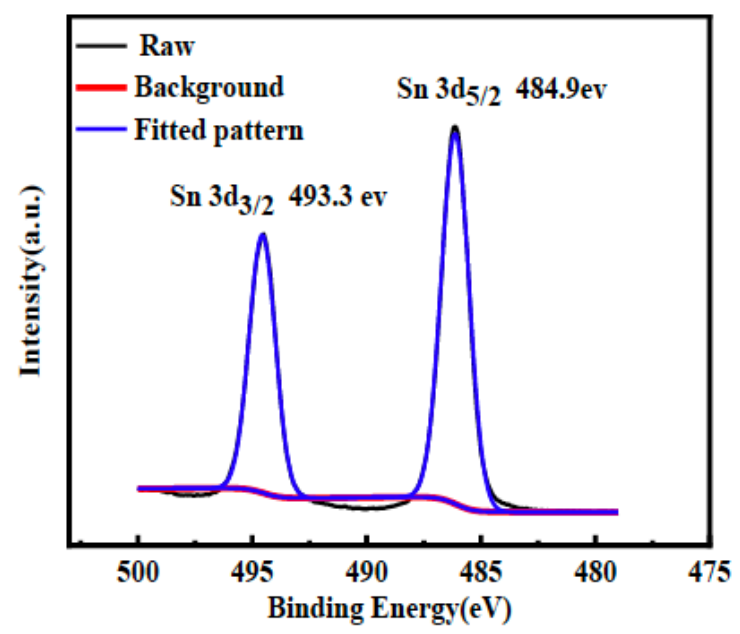

Figure 3

a. The XPS of Fe2O3, Fe2O3/C (the mass ratio of 3:1), Fe203/C@SnO2 (the mass ratio of 3:1:4), b highresolution curves of $\mathrm{c} \mathrm{Fe}, \mathrm{Sn}$, and $\mathrm{d} \mathrm{C}$. 
Sensing properties of the $\mathrm{Fe}_{2} \mathrm{O}_{3} / \mathrm{C} @ \mathrm{SnO}_{2}$ pressure sensor

a

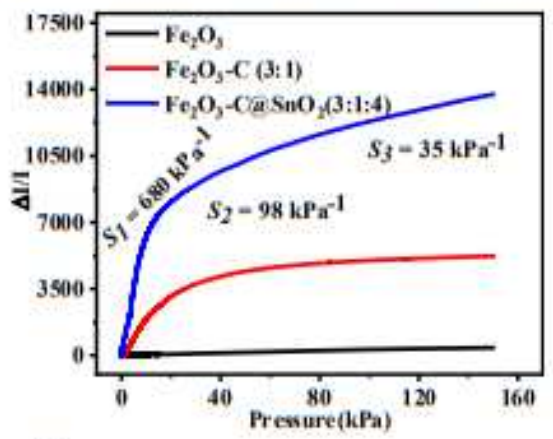

C

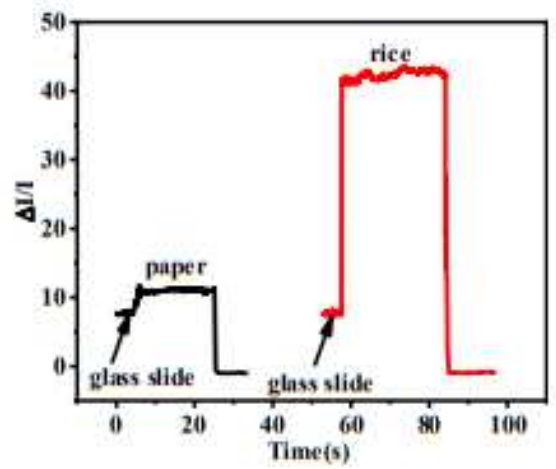

b

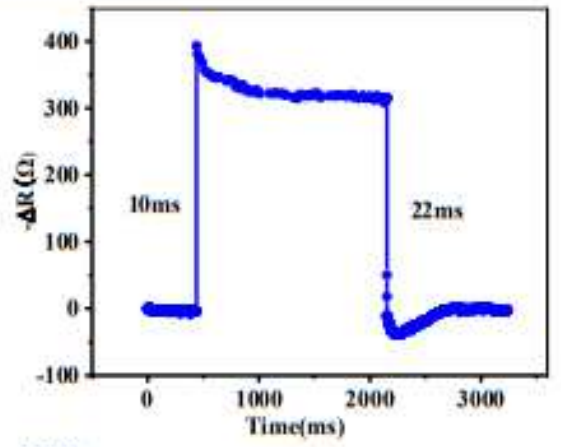

d

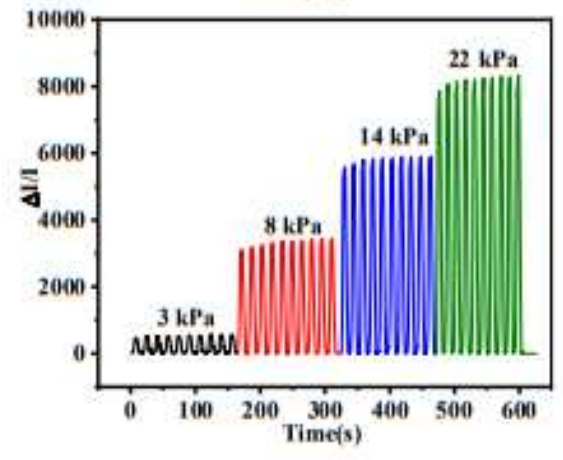

e

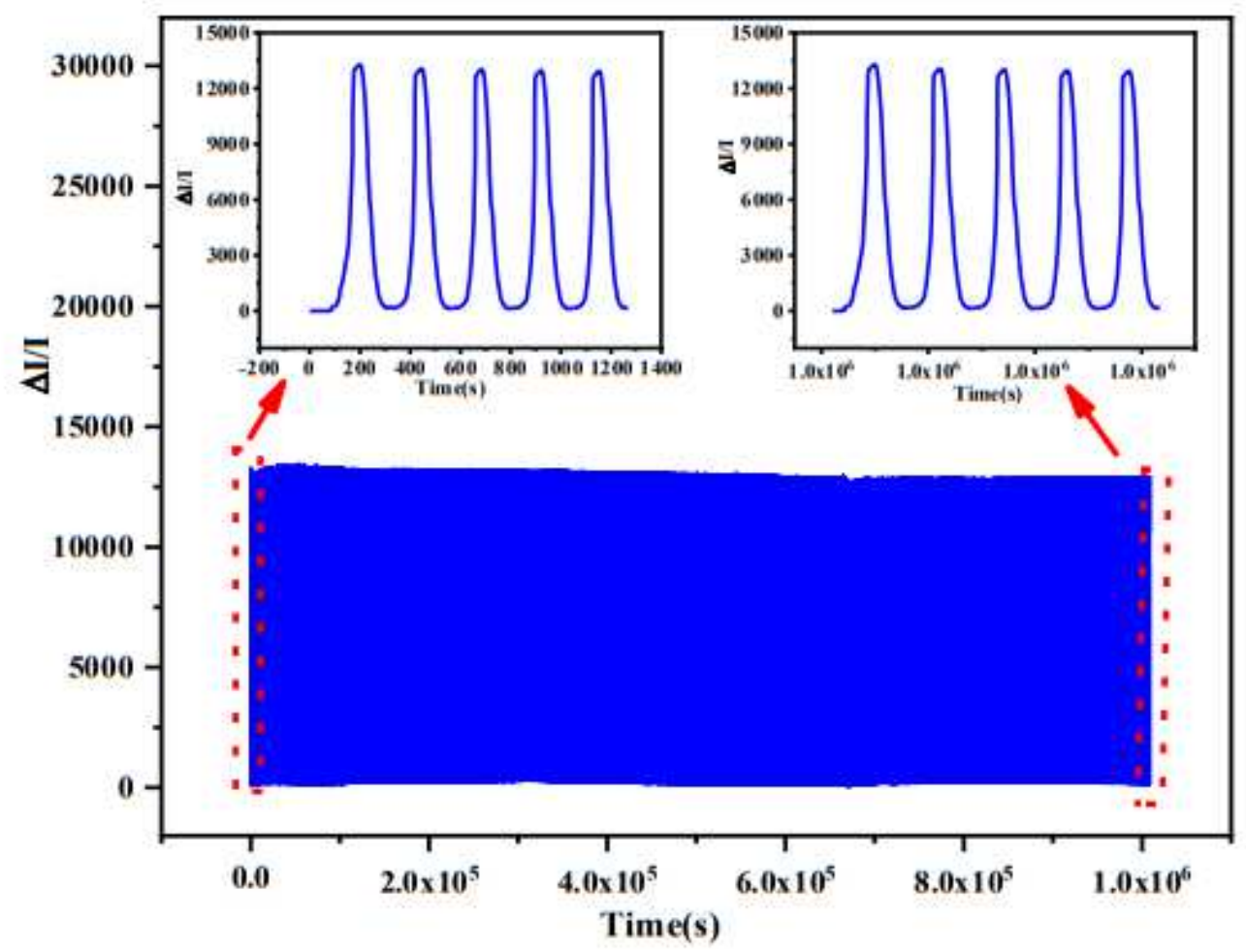

Figure 4

a The sensitivity of Fe203, Fe203/C with the mass of ratio of (3:1), and Fe203/C@SnO2 with the mass of ratio of 3:1:4 based sensors. b Response time of Fe203/C@Sn02 (3:1:4) pressure sensor. c Detection of weak pressure: current curve of the proposed Fe203/C@Sn02 (3:1:4) pressure sensor pressed by paper and rice grain. $d$ The current response due to increased pressures under loading and unloading. e 
Stability performance of the Fe2O3/C@SnO2 (3:1:4) pressure sensor with loadingunloading of more than 3500 cycles.

a

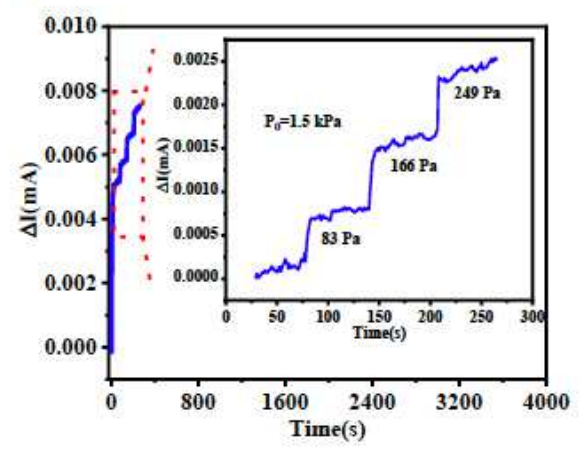

d

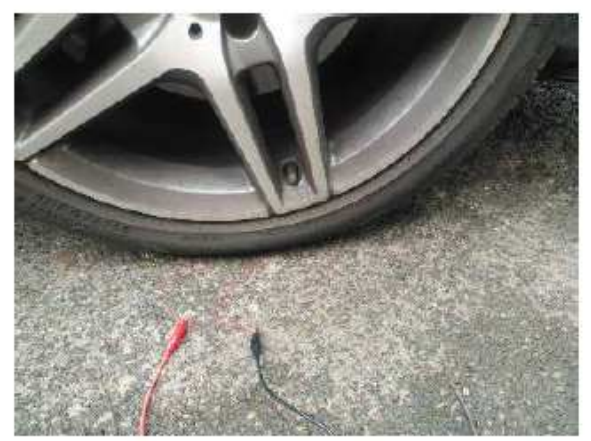

b

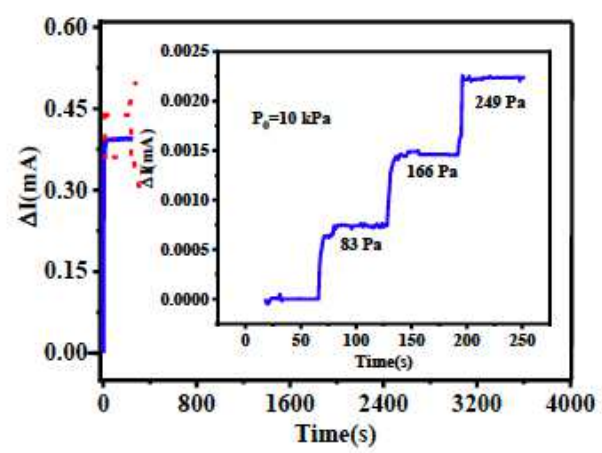

e

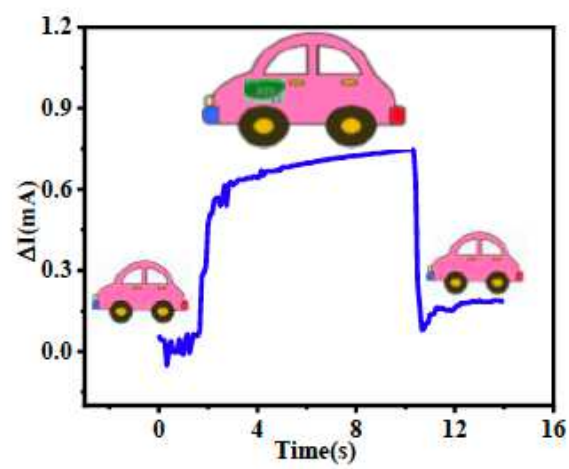

c

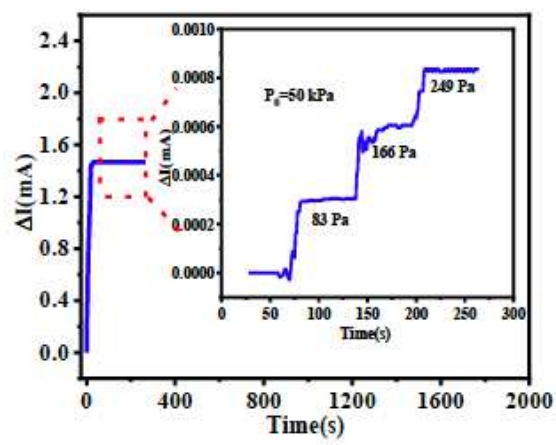

$\mathbf{f}$

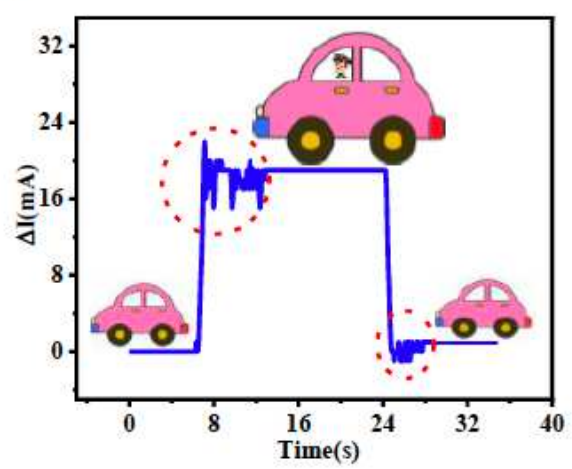

\section{Figure 5}

Detection of micro pressure under loading pressures of a $1.5 \mathrm{kPa}, \mathrm{b} 10 \mathrm{kPa}$, and c $50 \mathrm{kPa}$. d Experimental set-up of a car with a Fe203/C@SnO2 (3:1:4) pressure sensor attached under a front tire. e Current signals corresponding to an unloaded, loaded, and unloaded $4 \mathrm{~kg}$ carton of milk on the driving seat of the car. $\mathrm{f}$ Current signals corresponding to a $73 \mathrm{~kg}$ male passenger getting into and out of the car. 
a

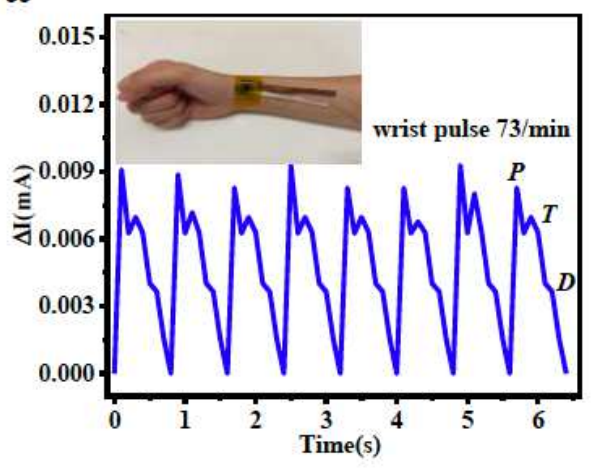

d

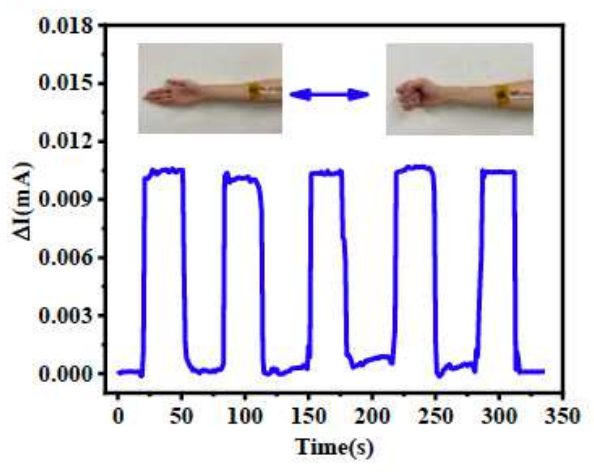

b

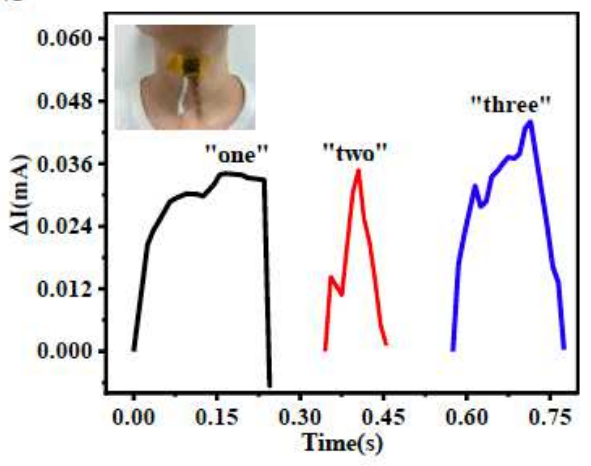

e

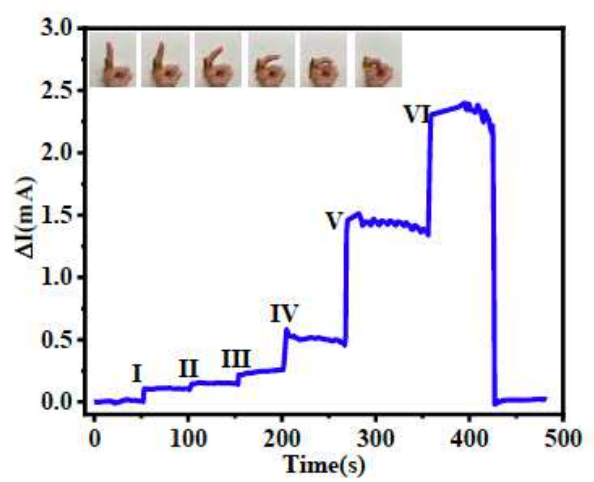

c

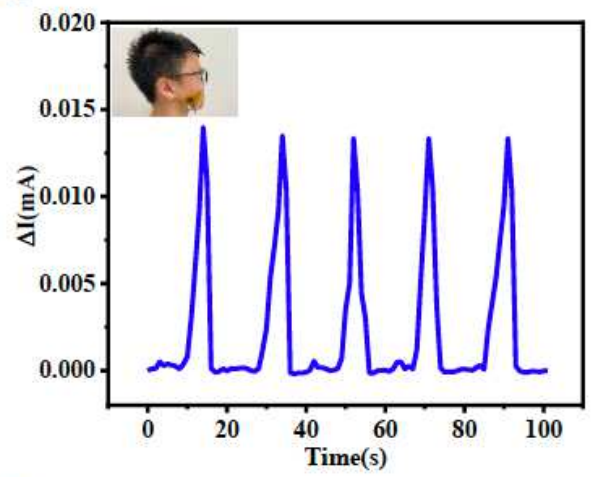

$f$

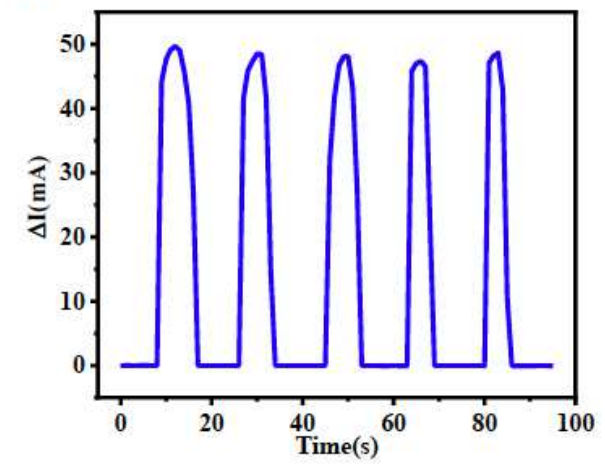

Figure 6

a The current response caused by the arterial pulse waves with the sensor attached to the wrist. $b$ The recorded current signal versus time pronouncing. Finally, $\mathrm{c}$ the signal variations of relative current corresponding to different occlusion, $d$ human palm, e finger motion, and $f$ walking.

\section{Supplementary Files}

This is a list of supplementary files associated with this preprint. Click to download.

- Supportinginformation.docx 